\title{
Tissue culture of Ophiorrhiza mungos L., a prospective method for the production of an anticancer drug, camptothecin
}

\author{
Geethu Gopinath $^{1}$, Binoy Jose ${ }^{1}, \mathbf{P}$ Ravichandran $^{2}$ and K Satheeshkumar ${ }^{1^{*}}$ \\ ${ }^{1}$ Biotechnology and Bioinformatics Division, Jawaharlal Nehru Tropical Botanic Garden and Research Institute, Palode, \\ Thiruvananthapuram 695562, India \\ ${ }^{2}$ Developmental Biology and Plant Biotechnology Laboratory, Sri Paramakalyani Centre for Excellence in Environmental Sciences, \\ Manonmaniam Sundaranar University, Alwarkurichi 627412, Tirunelveli, Tamil Nadu, India
}

\section{Article history}

Received: 23 October 2017 Accepted: 10 December 2017

Published: 01 January 2018

(c) Gopinath et al. (2018)

Editor

Ana Isabel Carvalho

Publisher

Horizon e-Publishing Group

Correspondence

K Satheeshkumar

\satheesh@jntbgri.res.in

\begin{abstract}
Camptothecin (CPT), a cytotoxic quinoline indole alkaloid, is an anticancer compound. Its two major semi synthetic derivatives, topotecan and irinotecan, are Food and Drug Administration (FDA) approved drugs effectively used for treating different cancer types and sold under the trade names Hycamtin and Camptosar. Among the Ophiorrhiza species, Ophiorrhiza mungos contains the highest CPT level $(0.02 \% \mathrm{~g} d w)$. CPT level was determined in plants before flowering $(0.074 \pm 0.003 \% \mathrm{~g} \mathrm{dw})$ and at flowering $(0.052 \pm$ $0.002 \% \mathrm{~g} \mathrm{dw}$ ). Multiple shoot cultures were induced on seedling-derived explants of $O$. mungos in half strength MS solid media supplemented with $1.0 \mathrm{mg} / \mathrm{L}$ BAP to obtain $12.00 \pm$ 1.22 shoots in 20 days. Repeated subcultures at 20 days interval yielded $20.00 \pm 3.71$ shoots/subculture of shoot clusters. After elongation, rooting and transplanting, the growth of shoot clusters were studied in both in vitro and same aged naturally grown seedlings. Highest biomass $(4.62 \pm 0.158 \mathrm{~g} \mathrm{fw})$ was obtained in in vitro-derived shoot clusters. CPT increased according to biomass and the maximum CPT was recorded in in vitro rooted shoot clusters after 15 days $(0.031 \pm 0.001 \% \mathrm{~g} \mathrm{dw})$. Hence, in vitro-derived rooted shoot clusters of $O$. mungos cultivated in net-pots for 60 days under shade net house conditions found to be a sustainable source for CPT.
\end{abstract}

Keywords: Camptothecin; multiple shoots; Ophiorrhiza mungos; shoot clusters; HPLC

Abbreviations: BAP, 6-benzylaminopurine; CPT, Camptothecin; dw, Dry weight; FDA, Food and Drug Administration; fw, Fresh weight; GA3, Gibberellic acid; IAA, indole-3-acetic acid; IBA, indole-3-butyric acid; NAA, a-naphthalene acetic acid.

Citation: Gopinath G, Jose B, Ravichandran P, Satheeshkumar K. Tissue culture of Ophiorrhiza mungos L., a prospective method for the production of an anticancer drug, camptothecin. Plant Science Today 2018;5(1):1-8. doi: 10.14719/pst.2018.5.1.359

\section{Introduction}

Camptothecin (CPT) is an essential precursor of semisynthetic chemotherapeutic agents (irinotecan, topotecan, etc.) for various forms of cancers throughout the world. The market value of CPT and its derivatives are US\$ 5000-8000 per kilogram and its demand in the world market is US \$ 2.2 billion (1). Due to the escalating demand and the rapid growth of market for CPT, raw material for extracting CPT is still from the natural sources. It has been reported 
that Camptotheca acuminata and Nothapodytes nimmoniana are the two important species primarily identified as the source of CPT and unsustainable extraction of these plants from the wild resulted both species pushed towards finding a place in IUCN redlist (2). Many efforts have already been initiated to map the population of $C$. acuminata and $N$. nimmoniana in India and China $(3,4)$. In addition to these two species, many other species also reported to contain CPT namely Ervatamia heyneana (5), Merrilliodendron megacarpum (6), Mostuea brunonis (7), Pyrenacantha klaineana (8), Chonemorpha grandiflora (9) and Miquelia dentata (10) which are either trees or lianas. CPT was also reported from some endophytic fungi (11). Various species of genus Ophiorrhiza have also been identified as a source of CPT, that are O. mungos (12), O. pumila, O. filistipula $(13,14)$, O. liukiuensis, O. kuroiwai (15), O. trichocarpon (16), O. rugosa var. prostrata (17), $O$. eraiantha (18), among others. However, maximum CPT was reported from $O$. mungos and it has been recognized as a potential source of CPT $(12,19)$. Considering the growing demand for CPT together with the importance of conservation of Ophiorrhiza species, development of alternate strategies for the production of the compound is significant $(20,21)$.

O. mungos (family Rubiaceae), a herbaceous medicinal plant is selected for the present investigation. The plant is distributed in the evergreen forests of the Western Ghats (India). Roots of the plant are traditionally used for treating snakebite and cancer, whereas the root bark possesses sedative and laxative properties (22-24). Recent reports revealed that the plant is also under severe pressure on its existence due to injudicious collection from the wild (25). Since distribution of $O$. mungos is limited in natural forests and the specific microclimatic condition in the evergreen forests is difficult to be reproduced for cultivation in the plains, it is necessary to develop alternative methods for large scale multiplication and consistent production of the compound. Plant tissue culture methods have already been identified as a suitable alternative for large-scale production of propagules and production of secondary metabolites (26). The present work describes a prospective tissue culture method for sustainable production of rooted multiple shoots and their net-pot cultivation in a shade net house leading to the extraction of CPT.

\section{Materials and methods Culture initiation}

Mature capsules from the plants maintained in the shade net house were collected during the months of September and October. The capsules were treated with $0.1 \%$ mercuric chloride $\left(\mathrm{HgCl}_{2}\right)(\mathrm{w} / \mathrm{v})$ for 3-7 min. After that the capsules were washed with sterile distilled water for 3-4 times and pressed with sterile forceps to release seeds with $0.36 \pm 0.1 \mathrm{~mm} \mathrm{~L} \mathrm{x} 0.28 \pm 0.9 \mathrm{~mm} \mathrm{~W}$. The seeds were again washed in sterile distilled water for $3-4$ times before transferring them on to Murashige and Skoog (MS) medium full, half and quarter strength basal media. The $\mathrm{pH}$ of the medium was adjusted to 5.8 before adding $0.6 \%(\mathrm{w} / \mathrm{v})$ agar (Thomas Baker, Mumbai) and autoclaved under pressure $\left(1.5 \mathrm{~kg} / \mathrm{cm}^{2}\right)$ for $18 \mathrm{~min}$ at $121{ }^{\circ} \mathrm{C}$. All the cultures were maintained at $26 \pm 2{ }^{\circ} \mathrm{C}$ under an illumination of white fluorescent tube lights (35-50 $\left.\mu \mathrm{Em}^{-1} \mathrm{~s}^{-1}\right)$ at $12 \mathrm{~h}$ photoperiod.

\section{Shoot multiplication}

After 2-3 weeks of seed germination, shoot portion was transferred vertically on to half strength MS solid medium supplemented with $3 \%$ sucrose and 0.2-3.0 mg/L 6-benzylaminopurine (BAP) either alone or in combinations with $0.1-1.0 \mathrm{mg} / \mathrm{L} \mathrm{a-}$ naphthalene acetic acid (NAA) or $0.1-1.0 \mathrm{mg} / \mathrm{L}$ indole-3-acetic acid (IAA).

After three weeks of multiple shoot induction, shoot clusters each with $4.1 \pm 0.8$ shoot buds from the multiple shoots were dissected out and subcultured to culture bottles containing 25 $\mathrm{ml}$ half strength MS agar medium supplemented with $3 \%$ sucrose and 0.2-2.0 mg/L BAP either alone or in combinations with $0.1-1.5 \mathrm{mg} / \mathrm{L}$ NAA or 0.1$1.5 \mathrm{mg} / \mathrm{L}$ IAA. Multiplication of shoots was achieved through repeated subcultures of shoot clusters $(4.1 \pm 0.8$ shoots/cluster $)$ at three week intervals. For shoot elongation, the shoots $(2.0 \pm$ $0.5 \mathrm{~cm}$ long) obtained from seedling derived explants were dissected in clusters with an average of $4.4 \pm 0.7$ shoots buds and inoculated on to half strength MS medium supplemented with Gibberellic acid $\left(\mathrm{GA}_{3}\right)(0.2$ to $2.0 \mathrm{mg} / \mathrm{L}$ ) or medium devoid of hormones.

\section{Rooting and hardening of shoot Clusters}

After the $6^{\text {th }}$ subculture, each shoot cluster from individual bottles was divided. Each subcluster consisted of an average of $6.1 \pm 1.8$ shoots $(2.2 \pm$ $0.53 \mathrm{~cm}$ long) and it was transferred to half strength MS basal solid medium supplemented with either 0.2-3.0 mg/L indole-3-butyric acid (IBA) or IAA alone or combinations with IAA and IBA $(0.2$ and $0.5 \mathrm{mg} / \mathrm{L})$ to induce rooting. The in vitro rooted shoot clusters were weaned away from the bottles (after 3 weeks), washed in running tap water to remove media remnants and planted in net-pots $(35 \times 30 \mathrm{~mm})$ filled with sand and farmyard manure (3:1) and kept them under the shade net house with proper watering to study growth and to estimate the level of CPT at different periods of rearing.

\section{Estimation of CPT}

CPT was also estimated in the in vitro-derived multiple shoots after the subculture. Detailed comparative analysis of growth (number of shoots 
Table 1. Multiple shoot induction in subcultured aseptic shoots in half strength MS solid media with different growth hormones. Observations were taken after 20 days of subculture. Mean values with different superscripts within columns are significantly different $(p \leq 0.05)$ by the Duncan's multiple range Least Significant Difference test.

Concentration (mg/L)of growth hormones

\begin{tabular}{|c|c|c|c|c|}
\hline BAP & NAA & IAA & (Mean \pm S.E) & (Mean \pm S.E) \\
\hline 0.2 & 0 & & $3.00 \pm 1.22^{\mathrm{e}}$ & $0.82 \pm 0.16^{\text {ef }}$ \\
\hline 0.5 & 0 & & $10.80 \pm 0.83^{b}$ & $0.68 \pm 0.13^{e}$ \\
\hline 1.0 & 0 & & $12.00 \pm 1.22^{\mathrm{a}}$ & $0.58 \pm 0.08^{f}$ \\
\hline 1.5 & 0 & & $10.00 \pm 1.22^{\mathrm{b}}$ & $0.54 \pm 0.05^{f}$ \\
\hline 2.0 & 0 & & $7.60 \pm 1.67^{c}$ & $0.50 \pm 0.07^{\mathrm{f}}$ \\
\hline 0.5 & 0.1 & & $5.00 \pm 0.70^{\mathrm{d}}$ & $0.82 \pm 0.13^{\text {ef }}$ \\
\hline 1.0 & 0.5 & & $2.80 \pm 0.83^{\mathrm{e}}$ & $1.18 \pm 0.17^{\mathrm{d}}$ \\
\hline 1.5 & 1.0 & & $2.60 \pm 0.89^{\mathrm{e}}$ & $1.08 \pm 0.35^{\mathrm{de}}$ \\
\hline 2.0 & 1.5 & & $2.80 \pm 0.83^{\mathrm{e}}$ & $1.52 \pm 0.37^{\mathrm{bc}}$ \\
\hline 0.5 & & 0.1 & $4.60 \pm 1.14^{\mathrm{d}}$ & $1.22 \pm 0.19^{d}$ \\
\hline 1.0 & & 0.5 & $3.20 \pm 1.09^{\mathrm{a}}$ & $1.38 \pm 0.19^{\text {cd }}$ \\
\hline 1.5 & & 1.0 & $2.40 \pm 1.14^{\mathrm{a}}$ & $1.68 \pm 0.40^{\mathrm{ab}}$ \\
\hline 2.0 & & 1.5 & $2.40 \pm 1.14^{\mathrm{a}}$ & $1.86 \pm 0.19^{\mathrm{a}}$ \\
\hline
\end{tabular}

in a cluster, length of shoots, plant biomass) and CPT content in varied sources of plants during netpot cultivation was carried out up to sixty days. 1000 plants were transferred for the experiment. The experiment was repeated twice. Growth (fresh weight) and CPT content were determined in the in vitro-derived rooted individual shoots, rooted shoot clusters, same aged natural seedlings planted in the net-pots, field-grown plants before flowering (4-5 months old), and plants at flowering stage (6 months old). All the samples were air dried separately and CPT was quantified using HPLC using a method described earlier (19). Quantitation was done by comparing the standard curve plotted using different concentrations of authentic CPT (Sigma Aldrich, USA), each taken in triplicate. The consistency of shoot multiplication and CPT production was checked by repeating the net-pot cultivation experiments with 800 plants from the same stock of in vitro plants.

HPLC was performed with a general purpose C18 Kromasil column ( $250 \times 4.6 \mathrm{~mm})$ attached to Gilson 321 binary gradient HPLC system. The mobile phase was acetonitrile-water (30:70) at a flow rate of $1 \mathrm{ml} / \mathrm{min}$ with a sample size of $15 \mu \mathrm{l}$ and the compound was determined in a detector (Gilson UV/VIS 156) attached to the HPLC at 254 nm. Quantitation of CPT was done by both spectrophotometer and HPLC and the results were presented as \% of CPT on gram (g) dry weight basis. The plants were dried under shade until the samples obtained constant dry weight.

\section{Statistical Analysis}

Data were subjected to analysis of variance (ANOVA) and means were compared by Duncan's multiple range Least Significant Difference (LSD) test at $95 \%$ significance level.

\section{Results and discussion \\ Culture initiation and multiplication}

Tissue culture multiplication in $O$. mungos using seedling-derived explants was already reported (27). Seed cultured in the media responded positively irrespective of the strength of the media. However, half strength MS basal media was best for $100 \%$ seed germination. After three weeks, individual seedlings of $2.0 \pm 0.3 \mathrm{~cm}$ were taken and root portion of the seedlings were removed and shoot portion with one pair of leaves $(1.54 \pm 0.2$ $\mathrm{cm}$ ) was used for shoot bud initiation. Maximum number of shoots was obtained in half strength MS solid media containing $1.0 \mathrm{mg} / \mathrm{L}$ BAP $(6.00 \pm 0.07)$. Shoot formation was from the base as well as node of the shoot. It was interesting to note that low concentration of BAP alone was favorable for multiple shoot induction. Shoot multiplication was comparatively poor in media containing either higher concentration of BAP alone or in combination with auxins. After 3 weeks, the newly raised shoot buds were inoculated on to half strength media containing varied levels of hormones for multiplication of shoots. Maximum number of shoots $(12.00 \pm 1.22)$ with a mean length of $0.58 \pm 0.08 \mathrm{~cm}$ was obtained in half strength MS 

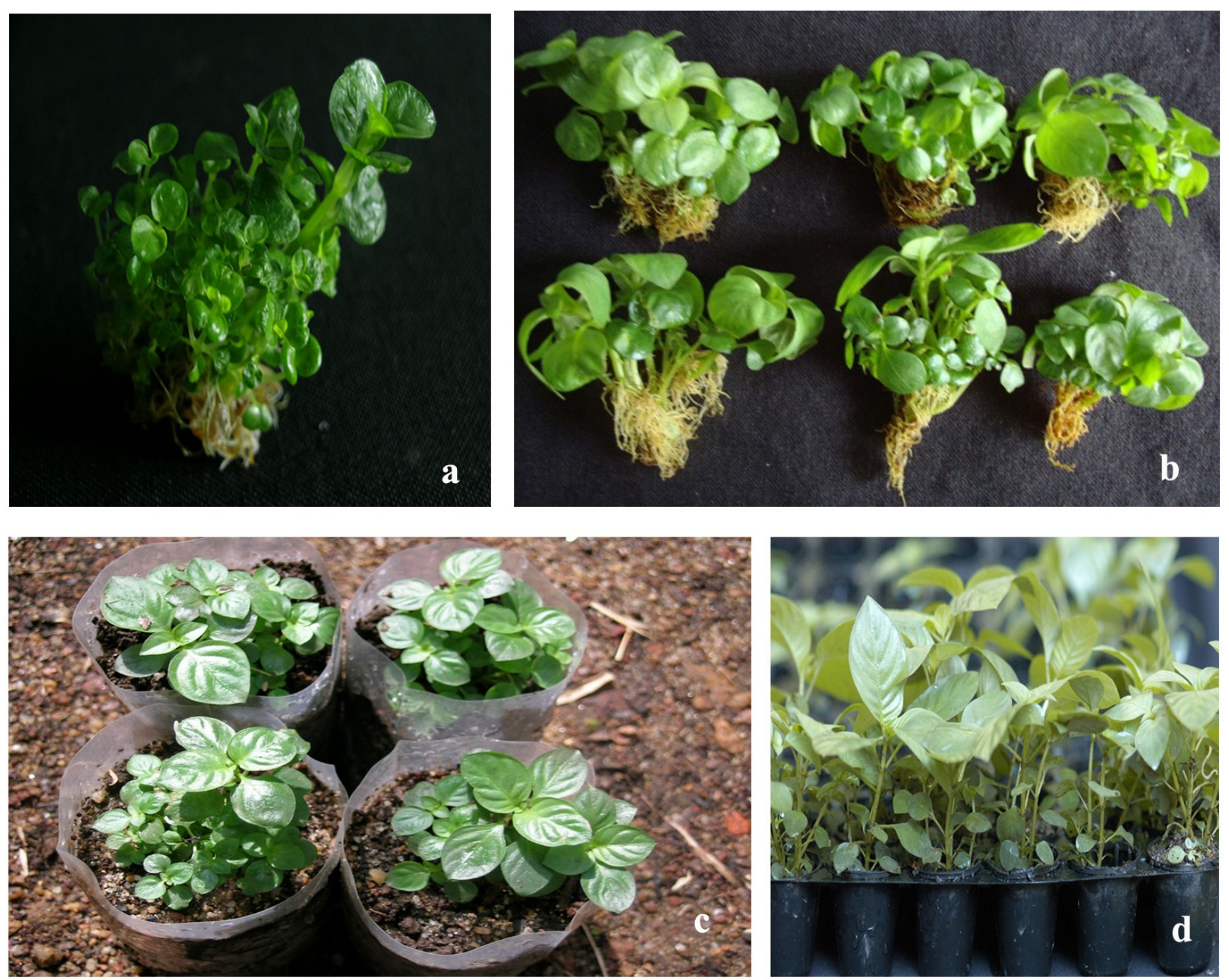

Fig. 1. Multiplication, rooting and hardening of $O$. mungos. (a) in vitro multiple shoot, (b) rooted shoot clusters, (c) established shoot clusters under the shade net house, (d) rooted shoot clusters grown in net pots for 60 days

solid medium supplemented with $1.0 \mathrm{mg} / \mathrm{L}$ BAP within 3 weeks (Table 1). Shoot proliferation was mostly from the axillary meristem of the basal part of the shoot. Shoots subcultured in media with the combinations of BAP and auxins (IAA or NAA) also found supportive for multiplication induction at the same frequency $(98 \%)$ but the shoots formed were short $(0.51 \pm 0.1 \mathrm{~cm})$ and associated with callusing particularly from the cut ends. So further subculture and multiplication of shoots obtained from media containing BAP only were considered. Maximum shoot proliferation was obtained $(20.00 \pm 3.71)$ in media with $0.5 \mathrm{mg} / \mathrm{L}$ BAP (Fig. 1a). The use of BAP at low concentration for multiple shoot formation through subculture of individual shoots in the present study is in contrast to the results published in $O$. prostrata where combination of BAP and IBA was used for maximum shoot proliferation (28).

During the successive subculture passages, the mean number and length of the shoots was found reduced $(0.75 \mathrm{~cm})$ and it might be due to the known inhibitory influence of media salts and cytokinin. A gradual decline in shoot multiplication was evident after the $6^{\text {th }}$ subculture. A similar result was reported earlier in the shoot cultures of species like Potentialla fruiticosa (29) and Trichopus zeylanicus (30) presumably due to habituation of shoots in enriched media composition. Efforts to maintain the rate of shoot multiplication by reducing the salt concentration to quarter strength, helped to overcome the problem of shoot multiplication and vigor. This result are in correlation with the report of $O$. trichocarpon (31) in which subculture of shoots alternatively to half strength and quarter strength MS media supported the induction of more multiple shoots.

\section{Elongation, rooting and establishment of shoot clusters}

For elongation, shoot clusters with $4.4 \pm 0.7$ shoots were subcultured in half strength MS media with different concentrations of GA3. Elongation was prominent in media containing $0.5 \mathrm{mg} / \mathrm{L}$ GA3. After the $6^{\text {th }}$ subculture, sub-clusters (each with an average of $6.1 \pm 1.8$ shoots) transferred for rooting were readily responded to rooting in presence of auxins within 10 days. Maximum formation of $43.60 \pm 5.50$ roots without callusing was recorded in presence of $1.5 \mathrm{mg} / \mathrm{L} \mathrm{IBA} \mathrm{(Fig.} \mathrm{1b).} \mathrm{Along} \mathrm{with}$ root formation, the shoots also got elongated 

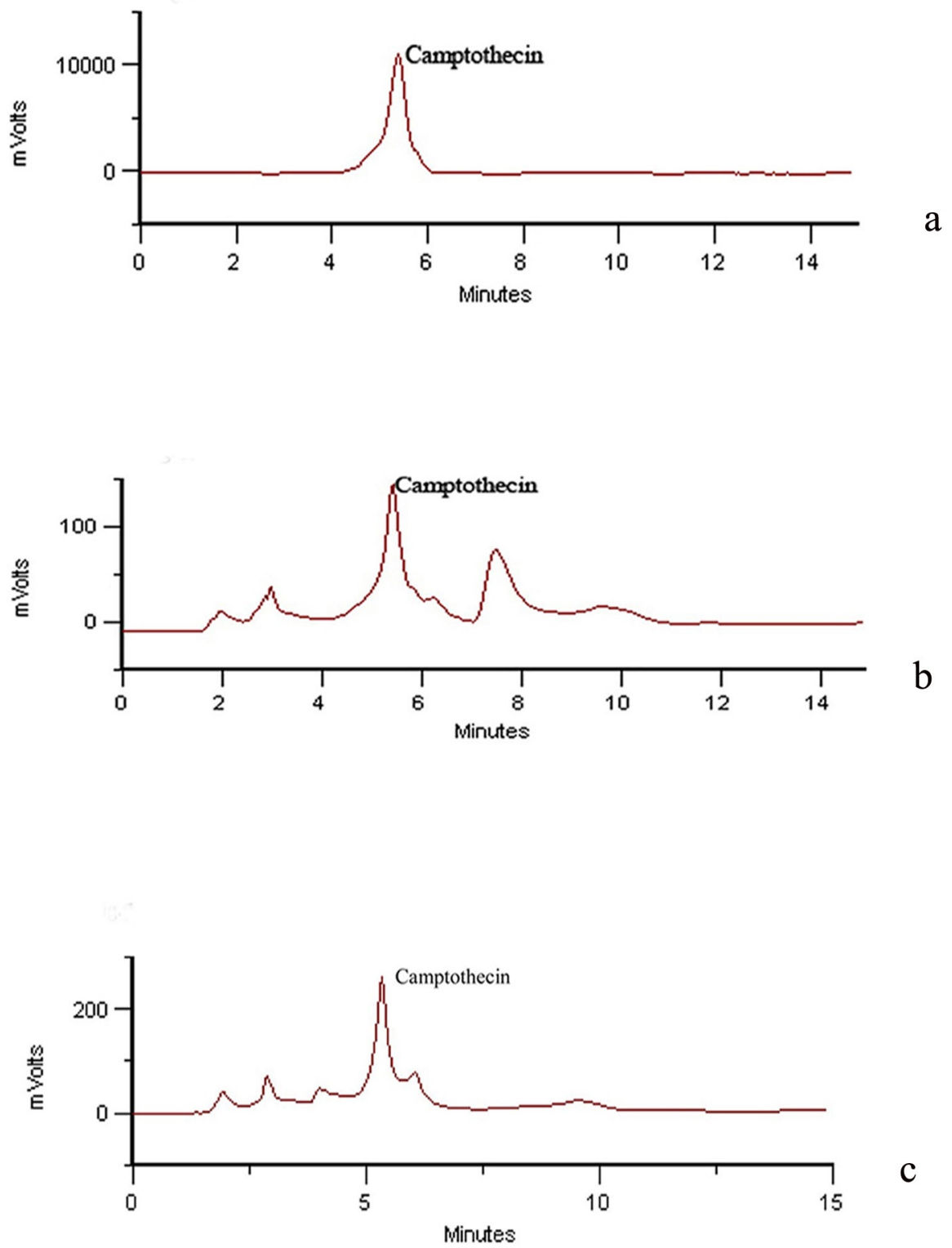

Fig. 2. HPLC chromatogram of CPT from different plant samples. (a) standard CPT, (b) plants at flowering stage, (c) plants grown for 60 days in net poots

further and attained a length of $3.25 \pm 0.45 \mathrm{~cm}$ in 3 weeks. The rooted shoot sub-clusters harvested were washed thoroughly in running tap water, showed $95 \%$ establishment under the shade net house with the formation new leaves within 10 days (Fig. 1c). It was calculated that each shoot from the seedlings derived multiple shoots can produce on average 288 shoot clusters and were easily rooted and established in egg trays (net-pots) within a period of 21 weeks. Following the procedure, an average of 2070 rooted shoot clusters could be amassed from a single shoot within the same period. It was observed that one sq.ft. egg tray holds 50 net-pots (50 rooted shoot clusters). Fresh weight of rooted shoot clusters during planting $(0.18 \pm 0.02 \mathrm{~g})$ was higher than the biomass of tissue culture-derived single plantlets $(0.121 \pm 0.04 \mathrm{~g})$ and naturally germinated same aged seedlings $(0.098 \pm 0.02 \mathrm{~g})$. Survival of all the shoots was observed up to 60 days and found that only less than 2 or 3 after a period of 90 days. A gradual increase in fresh weight $(4.62 \pm 0.158 \mathrm{~g})$ was recorded periodically and reached more than twenty-fold increase in biomass production after sixty days of growth (Fig. 1d). in vitro production of multiple shoots and production of plantlets with rooted shoot clusters and their field establishment is reported to be exceptional. Though rooting of in vitro flowered multiple shoots of bamboo and their successful field establishment without affecting the flowering and survival in the field was reported (32). However, establishment of multiple shoot cultures for enhanced compound production in medicinal plants is the first report in this regard.

A marginal increase in fresh weight of shoots in 15 days of growth was observed and it was continued up to 60 days in net-pots. After 60 days, the established plantlets (rooted shoot clusters) transplanted in 12' pots filled with sand and farmyard manure (2:1) mixture exhibited remarkable growth. It was noted that only $2.4 \pm 0.5$ 
shoots from the rooted shoot clusters retained and they profusely grew in to mature plants.

Table 2. Percentage of CPT determined in seedlings, roots and shoots in different developmental stages of $O$. mungos estimated using HPLC

\begin{tabular}{clc}
\hline $\begin{array}{c}\text { Sl. } \\
\text { No. }\end{array}$ & \multicolumn{1}{c}{ Sample } & $\begin{array}{c}\text { \% of CPT per g of } \\
\text { dry weight (Mean } \\
\pm \text { S.E) }\end{array}$ \\
\hline 1 & Seedlings (2 months old) & $0.022 \pm 0.001$ \\
\hline 2 & $\begin{array}{l}\text { Roots of field grown plants } \\
\text { before flowering }\end{array}$ & $0.030 \pm 0.001$ \\
\hline 3 & $\begin{array}{l}\text { Roots of field grown plants at } \\
\text { flowering }\end{array}$ & $0.030 \pm 0.001$ \\
\hline 4 & $\begin{array}{l}\text { Shoots of field grown plants } \\
\text { before flowering }\end{array}$ & $0.074 \pm 0.003$ \\
\hline 5 & $\begin{array}{l}\text { Shoots of field grown plants at } \\
\text { flowering }\end{array}$ & $0.052 \pm 0.002$ \\
\hline
\end{tabular}

\section{Estimation of CPT}

CPT content was determined in various sources and remarkable variation was detected. The shoots contained higher amount of CPT than roots. The results were presented in Table 2. A remarkable reduction in CPT level was noticed in plants during flowering stage. It was also estimated that CPT of in vitro grown multiple shoots contained $0.020 \pm 0.00 \% \mathrm{~g}$ dw CPT after subculture. Results on biomass and level of CPT in plants cultivated in net-pots at different periods of time are given in Table 3. Higher level of CPT was obtained in in vitro derived rooted shoot clusters established in net-pots after 15 days of growth $(0.031 \pm 0.001 \% \mathrm{~g} \mathrm{dw})$ and after that the level of CPT declined and become steady till the growth period of 60 days $(0.006 \pm 0.00 \% \mathrm{~g} \mathrm{dw})$. Repeated experiments also showed consistency in growth of shoots and CPT production. CPT content and biomass production during growth period are directly proportional to each other. Therefore, it is demonstrated that high level of CPT detected in 15 days old rooted shoot clusters might be a transient phenomenon as the time required to establish the plants with stable characters against new environment. The internal concentration of CPT in the shoots declined steadily after 15 days while the vegetative growth of the plants continued to increase. The results confirmed the enhanced yet transient production of the compound after transplanting the in vitro derived plants as clusters in net-pots. The exceptional synthesis and accumulation of CPT in micropropagated plants established for a short period as a transient feature is not reported by previous workers.

HPLC chromatogram of CPT also confirmed the authenticity of CPT in the dried samples (Fig. 2 $\mathrm{a}-\mathrm{c})$. Results on the difference in CPT concentration in the shoots of field grown plants of $O$. mungos at two different stages (6 month old at flowering stage and 4-5 month old plants before flowering) might be due to the defense mechanism developed in young plants against various stress as reported

Table 3. Growth and CPT production in rooted shoots established in net pots at different periods of growth. Mean values with different superscripts within columns are significantly different $(p \leq 0.05)$ by the Duncan's multiple range Least Significant Difference test

\begin{tabular}{|c|c|c|c|c|}
\hline $\begin{array}{l}\text { Period after } \\
\text { transfer to net pots } \\
\text { (days) }\end{array}$ & $\begin{array}{l}\text { Number of shoots } \\
\text { in a cluster } \\
(\text { Mean } \pm \text { S.E) }\end{array}$ & $\begin{array}{l}\text { Length of shoots (cm) } \\
(\text { Mean } \pm \text { S.E) }\end{array}$ & $\begin{array}{c}\text { Plant biomass: fresh } \\
\text { weight (g) } \\
(\text { Mean } \pm \text { S.E) }\end{array}$ & $\begin{array}{c}\text { \% of CPT per g of dry } \\
\text { weight } \\
(\text { Mean } \pm \text { S.E) }\end{array}$ \\
\hline 0 & $6.16 \pm 0.089^{a}$ & $4.24 \pm 0.030^{f}$ & $0.18 \pm 0.020^{\mathrm{i}}$ & $0.018 \pm 0.000^{\mathrm{cd}}$ \\
\hline 5 & $6.20 \pm 0.158^{\mathrm{a}}$ & $4.42 \pm 0.092^{\mathrm{f}}$ & $0.25 \pm 0.026^{\mathrm{i}}$ & $0.019 \pm 0.000^{c}$ \\
\hline 10 & $6.06 \pm 0.134^{\mathrm{a}}$ & $4.45 \pm 0.033^{\mathrm{f}}$ & $0.36 \pm 0.031^{\mathrm{i}}$ & $0.024 \pm 0.001^{b}$ \\
\hline 15 & $6.22 \pm 0.130^{\mathrm{a}}$ & $4.83 \pm 0.038^{\mathrm{e}}$ & $0.35 \pm 0.019^{i}$ & $0.031 \pm 0.001^{\mathrm{a}}$ \\
\hline 20 & $6.26 \pm 0.114^{\mathrm{a}}$ & $4.75 \pm 0.143^{\mathrm{e}}$ & $0.65 \pm 0.035^{h}$ & $0.022 \pm 0.001^{\mathrm{b}}$ \\
\hline 25 & $6.00 \pm 0.000^{a}$ & $4.30 \pm 0.158^{\mathrm{f}}$ & $0.95 \pm 0.035^{\mathrm{g}}$ & $0.017 \pm 0.003^{\mathrm{d}}$ \\
\hline 30 & $5.18 \pm 0.130^{b}$ & $4.36 \pm 0.148^{f}$ & $1.32 \pm 0.164^{\mathrm{f}}$ & $0.006 \pm 0.000^{\mathrm{e}}$ \\
\hline 35 & $5.36 \pm 0.207^{b}$ & $4.77 \pm 0.186^{\mathrm{e}}$ & $2.10 \pm 0.081^{\mathrm{e}}$ & $0.005 \pm 0.000^{\mathrm{e}}$ \\
\hline 40 & $4.28 \pm 0.178^{c}$ & $5.72 \pm 0.110^{d}$ & $2.75 \pm 0.036^{\mathrm{d}}$ & $0.005 \pm 0.000^{\mathrm{e}}$ \\
\hline 45 & $4.54 \pm 0.364^{c}$ & $5.75 \pm 0.425^{d}$ & $2.86 \pm 0.034^{\mathrm{d}}$ & $0.005 \pm 0.000^{\mathrm{e}}$ \\
\hline 50 & $5.46 \pm 0.320^{b}$ & $6.86 \pm 0.052^{c}$ & $3.74 \pm 0.418^{c}$ & $0.005 \pm 0.000^{\mathrm{e}}$ \\
\hline 55 & $4.48 \pm 0.349^{c}$ & $7.79 \pm 0.173^{b}$ & $4.20 \pm 0.447^{\mathrm{b}}$ & $0.006 \pm 0.000^{\mathrm{e}}$ \\
\hline 60 & $4.54 \pm 0.364^{c}$ & $8.61 \pm 0.338^{a}$ & $4.62 \pm 0.158^{a}$ & $0.006 \pm 0.000^{\mathrm{e}}$ \\
\hline
\end{tabular}


by Hoft et al. in 1996 (33). It is evident that the in vitro culture conditions particularly favor the biosynthetic ability of the plants in respect of CPT. Difference in alkaloid content at different stages of development in Atropa belladonna was already reported (34).

Though reports on CPT production through in vitro cultures are available $(5,35)$, the yield was 100 - to 1000 - fold lower than from the field grown plants. Induction of multiple shoots and regeneration of plants have been reported in many species of Ophiorrhiza such as $O$. mungos (36), $O$. pumila (14) and $O$. decumbens (37). The study of Namdeo et al. in 2012 (36) in O. mungos exhibited a higher level of CPT in in vitro plants $(0.0768 \%$ $\mathrm{w} / \mathrm{w})$ than in adventitious buds $(0.0026 \% \mathrm{w} / \mathrm{w})$. Undifferentiated callus cultures and suspension cultures of $C$. acuminata, $N$. nimmoniana and $C$. grandiflora also produced a significantly low amount of CPT $(38,35,9)$. Previous shoots culture of $O$. eriantha and $O$. pumila $(18,14)$ also showed lower level of CPT but root and hairy root cultures of $O$. pumila had less or the same CPT concentration of that registered in the field derived counterparts. Studies on comparative performance between tissue cultured plants and conventionally grown plants for secondary metabolite production are also rare (39).

CPT contents in $O$. mungos were reduced, ranging from $0.074 \pm 0.003 \% \mathrm{~g} d w$ to $0.052 \pm 0.002$ $\% \mathrm{~g} \mathrm{dw}$ after flowering. The chances of early uprooting of these plants may cause serious threat to its natural propagation through seeds. The present study shows an alternative method for rapid multiplication and production of rooted shoot clusters and their net-pot cultivation as an attractive system for high biomass and CPT production against the values recorded in the field grown plants or in vitro derived multiple shoots. The novelty of the study is the rooting of multiple shoots and their cultivation in net-pots for 60 days as a successful alternative technology for large scale propagation of $O$. mungos for enhanced production of $\mathrm{CPT}$ and thereby conserving the plants in the natural reserves.

\section{Author's contributions}

GG conducted the experiment and carried out the statistical analysis, BJ conducted the phytochemical analysis, RP consistent guidance, and SK designed the experiments and consistent guidance.

\section{Acknowledgements}

The authors thank the Director, Jawaharlal Nehru Tropical Botanic Garden and Research Institute, Thiruvananthapuram, for providing the necessary facilities.

\section{Competing Interest}

The authors have declared that there are no competing interests.

\section{References}

1. Newsletter. Hunan 3W Botanical Extracts Inc. Main land China. 2013.

2. Viraporn V, Yamazaki M, Saito K, Denduangboripant J, Chayamarit K, Chuanasa T, Sukrong S. Correlation of camptothecin-producing ability and phylogenetic relationship in the genus Ophiorrhiza. Planta Med. 2011;77:59-64. doi: 10.1055/s-0030-1250568

3. Kumar R, Ved DK. Red listed medicinal plants of conservation concern in Southern India. FRLHT, Bangalore. 2000; 261-3.

4. Namdeo AG, Sharma A, Mahadik KR. Some observations on Nothapodytes foetida: An overview. Phcog. Rev. 2008; 12: 110-15.

5. Gunasekera SP, Badawi MM, Cordell GA, Farnsworth NR, Chitnis M. Plant anticancer agents - Isolation of camptothecin and 9-methoxycamptothecin from Ervatamia heyneana. J.Nat. Prod. 1979; 42: 475-7. doi: 10.1021/np50005a006

6. Arisawa M, Gunasekera SP, Cordell GA, Farnsworth NR. Plant anticancer agents XXI.Constituents of Merrilliodendron megacarpum. Planta Med. 1981; 4: 404-7. doi: 10.1055/s-2007-971533

7. Dai JR, Cardellina JH, Boyd MR, 20-O-betaglucopyranosyl camptothecin from Mostueabrunonis: a potential camptothecin pro-drug with improved solubility. J. Nat. Prod. 1999; 62: 1427-9. doi: 10.1021/np990100m

8. Zhou BN, Hoch JM, Johnson RK, Mattern MR, Eng WK, Ma J, Hecht SM, Newman DJ, Kingston DG. Use of COMPARE analysis to discover new natural product drugs: isolation of camptothecin and 9methoxycamptothecin from a new source. J. Nat. Prod. 2000; 63: 1273-6. doi: 10.1021/np000058r

9. Kulkarni AV, Patwardhan AA, Lele U, Malpathak NP. Production of camptothecin in cultures of Chonemorpha grandiflora, Pharmacognosy Res. 2010; 2: 296-9. doi: 10.4103/0976-4836.72327

10. Thriveni HN, Ravikanth G, Vasudeva R, Ganeshiah KN, Umashankar R. Camptothecin and methoxy camptothecin from callus cultures of Miquelia dentata Bedd. A rare plant of the Western Ghats of India. Ind. J. Biotechnol. 2015; 14: 123-6.

11. Kusari S, Sebastian Z, Michael S. An endophytic fungus from Camptotheca acuminata that produces camptothecin and analogues. J. Nat. Prod. 2009; 72: 27. doi: 10.1021/np800455b

12. Tafur S, Nelson JD, Delong DC, Svoboda GH. Antiviral components of Ophiorrhiza mungos for isolation of camptothecin and 10-methoxycamptothecin Lloydia. 1976; 39: 261-2.

13. Aimi N, Nishimura M, Miwa A, Hoshino H, Sakai S, Hagniwa J. Pumiloside and deoxy pumiloside; possible intermediate of camptothecin biosynthesis.Tetrahedron Lett.1989; 30: 4991-4. doi: 10.1016/S0040-4039(01)80563-3

14. Saito K, Sudo H, Yamasaki M, Koseki-Nakamun M, Kitajima M, Takayama H, Aimi N. Feasible production of camptothecin by hairy root cultures of Ophiorrhiza pumila. Plant Cell Rep. 2001; 20: 267-71. doi: 10.1007/s002990100320

15. Asano T, Watase I, Sudo H, Kitajima M, Takayama H, Aimi N, Yamasaki M, Saito K. Camptothecin production by in vitro cultures of Ophiorrhiza 
liukiuensis and O.kuroiwai. Plant Biotech. 2004; 24: 275-81. doi: 10.5511/plantbiotechnology.21.275

16. Klausmeyer P, McCloud TG, Melillo G, Scudiero DA, Cardellina JHI, Shoemaker RH. Identification of a new natural camptothecin analogue in targeted screening for HIF-1á inhibitors. Planta Med. 2007; 73: 49-52. doi: 10.1055/s-2006-951767

17. Gharpure G, Chavan B, Lele U, Hastak A, Bhave Malpure N. Camptothecin accumulation in Ophiorrhiza rugosa var. prostrata from northern Western Ghats. Curr.Sci. 2010; 98: 302-4.

18. Rani VKJ, Fijesh PV, Jose Padikkala. Micropropagation of Ophiorrhiza eriantha Wight. through leaf explant cultures. Plant Tissue Cult. Biotechnol. 2010; 20: 13-20.

19. Renjith R, Sibi CV, Rajani K, Roja G, Ramaswamy V, Krishnan S, Sabulal B. Search for Camptothecin yielding Ophiorrhiza species from southern Western Ghats in India: A HPTLC-densitometry study. Ind. Crop Prod. 2013; 43: 472-76. doi: 10.1016/j.indcrop.2012.07.054

20. Wink M. Biochemistry of plant secondary metabolism. In: Wink $M$ (ed.) Annual Plant Reviews. Sheffield Academic Press and CRC Press. 2003; 1-16.

21. Watase I, Sudo H, Yamazaki M, Saito K. Regeneration of transformed Ophiorrhiza pumila plants producing camptothecin. Plant Biotech. 2004; 21: 337-42. doi: 10.5511/plantbiotechnology.21.337

22. NISCAIR. The Wealth of India. A dictionary of Indian Raw Materials and Industrial Products, Publication and information Directorate CSIR, New Delhi, India, 1966; 98.

23. Kirtikar KR, Basu BD. Indian Medicinal Plants (Bishen Sing Mahendrapal, New Delhi, India). 1975; 11: 1268-9.

24. Houghton PJ. Plants used to treat snakebite. ASOMPS. 1994; 3: 141.

25. Giri CC, Shyamkumar B, Anjaneyulu C. Progress in tissue culture, genetic transformation and applications of biotechnology to trees: an overview. Trees. 2004; 18:11535. doi: 10.1007/s00468-003-0287-6

26. Roja G. Micropropagation and production of Camptothecin from in vitro plants of Ophiorrhiza rugosa var. decumbens .Nat. Prod. Res. 2008; 22: 1017 -23. doi: 10.1080/14786410802006165

27. Jose B, Satheeshkumar K. In vitro mass multiplication of Ophiorrhiza mungos Linn. Indian J. Exp. Biol. 2004;640-2.

28. Beegum AS, Martin KP, Zhang CL, Nishitha IK, Ligimol Slater A, Madhusoodanan PV. Organogenesis from leaf and internode explants of Ophiorrhiza prostrata, an anticancer drug (camptothecin) producing plant. Electron. J. Biotechnol. 2007; 10: 1-10. doi: 10.2225/vol10issue1-fulltext-7
29. Remphery WR, Palmer CE, Blouw MJ. In vitro branching in relation to repeated subculture in two cultivars of Potentialla fruiticosa. Plant Cell Tiss.and Org. Cult. 1993; 235-40.

30. Krishnan PN, Sudha CG, Seeni S. Rapid propagation through shoot tip cultures of Trichopus zeylanicus Gaertn, a rare ethanomedicinal plant. Plant Cell Rep. 1995; 14: 708-11.

31. Sibi CV, Dintu KP, Renjith R, Krishnaraj MV, Roja G and Satheeshkumar K, A new record of Ophiorrhiza trichocarpon Blume (Rubiaceae: Ophiorrhizeae) from Western Ghats, India: Another source plant of camptothecin. J Sci Res. 2012; 4: 529-32. doi: 10.1007/BF00232652

32. Lin CS, Lin CC, Chang WC. In vitro flowering of Bambusa edulis and subsequent plantlet survival. Plant cell Tiss. and Org. Cult. 2003; 72: 71-8.

33. Hoft M, Verpoorte R, Beck E. Growth and alkaloid contents in leaves of Tabernaemontana pachysiphon Stapf (Apocynaceae) as influenced by light intensity, water and nutrient supply. Oecologia. 1996; 107: 160-9. doi: 10.1007/BF00327899

34. Elzenga G, Bruyn JW. Interrelation of alkaloid content and stage of development of 1- and 2-yearold Atropa belladonna L. Euphytica. 1956; 5: 25966. doi: 10.1007/BF00038847

35. Roja M, Heble MR. The quinoline alkaloids camptothecin and 9 -methoxy camptothecin from tissue cultures and mature trees of Nothapodytes foetida. Phytochemistry. 1994; 36: 65-6. doi: 10.1016/S0031-9422(00)97013-4

36. Namdeo G, Priya T. Bhosale BB. Micropropagation and production of camptothecin form in vitro plants of Ophiorrhiza mungos. Asian Pac J Trop Biomed.2012; 2: S662-S666. doi: 10.1016/S22211691(12)60292-5

37. Roja G. Micropropagation and production of Camptothecin from in vitro plants of Ophiorrhiza rugosa var. decumbens. Nat Prod Res.2008; 22 (12):1017-23. doi: 10.1080/14786410802006165

38. Sakato K, Tanaka H, Mukai N, Misawa M. Isolation and identification of camptothecin from cell of Camptotheca acuminata suspension cultures. Agri. Bio. Chem. 1974; 38: 217-18. doi: 10.1080/00021369.1974.10861136

39. Satheeshkumar $\mathrm{K}$, Seeni $\mathrm{S}$. In vitro mass multiplication and production of roots in Plumbago rosea L. Planta Med. 2003; 69: 83-6. doi: 10.1055/s2003-37035 